\title{
JUSTIÇA EM ESPINOSA: NOTAS PARA UMA HIPÓTESE
}

\section{LUIZ CARLOS MONTANS BRAGA ${ }^{1}$}

RESUMO: Uma das agudezas de Espinosa consiste em fazer uso de termos da tradição e dar a eles novas cores, subvertendo-os. Com efeito, Deus, conceito-chave em seu sistema, equivale a natureza ou substância. Não ato puro e transcendente, como em Tomás de Aquino, mas imanente. Direito, por seu turno, é o mesmo que potentia, derivado da potência absoluta da substância ou natureza. Tese que, importa sublinhar, estiola por completo a divisão estanque direito natural versus direito positivo, visto que todo direito é por definição potência, sendo, por esta razão, o direito natural em estado de natureza mera opinião, como escreve no Tratado político. O mesmo se dá com outros conceitos, tais como liberdade e afetos. O objetivo do artigo é tratar de um conceito menos frequentado pelos comentadores, mas que, hipótese que será defendida, é igualmente reconceitualizado por Espinosa. Trata-se do conceito de justiça. O foco inicial será Tomás de Aquino, como autor paradigmático da tradição que analisa o conceito de justiça. Isto para, por contraste, explicitar em quê Espinosa modifica a definição. Com este objetivo, o escólio 2 da Proposição 37 da Parte IV da Ética será analisado à luz do sistema espinosano. Isso implica que outras partes do corpus serão movimentadas para a compreensão deste excerto central da Ética quanto ao tema da justiça. A questão-chave que norteará a exposição será a seguinte: Espinosa possui um conceito de justiça? Se sim, ele se distancia da tradição, aqui representada por Tomás de Aquino? Por fim, trata-se de investigar se há um, e apenas um, conceito de justiça espinosano.

PALAVRAS-CHAVE: Espinosa; Tomás de Aquino; reconceitualização; justiça; cidade.

ABSTRACT: One of Spinoza's sharp points is to make use of traditional terms and give them new colors, subverting them. Indeed, God, a key concept in his system, is equivalent to nature or substance. Not a pure and transcendent act, as in Thomas Aquinas, but immanent. Right, in turn, is the same as potentia, derived from the absolute potency of the substance or nature. Thesis that, it is important to underline, completely ends the division of natural versus positive right, since every right is by definition power, and for this reason, natural right in a state of nature is mere opinion, as Spinoza writes in the Political Treatise. The same is true of other concepts, such as freedom and affects. The objective of the article is to deal with a concept that is less frequented by commentators, but that, a hypothesis that will be defended, is also reconceptualized by Espinosa, namely, the concept of justice. The initial focus will be Thomas Aquinas, as the paradigmatic author of the tradition that analyzes the concept of justice. This contrast makes clear how Spinoza modifies the definition. For this purpose, the scholium 2 of Proposition 37 of Part IV of the Ethic will be analyzed in the light of Spinoza's system. This implies that other parts of the corpus will be moved to the understanding of this central excerpt from the Ethic on the theme of justice. The key question that will guide the essay will be the

\footnotetext{
${ }^{1}$ Professor de Filosofia da Universidade Estadual de Feira de Santana (UEFS). Doutor em Filosofia pela Pontifícia Universidade Católica de São Paulo (PUC-SP) e mestre em Direito pela Universidade de São Paulo (USP). Email: lcmbraga@uefs.br.
} 
following: does Spinoza have a concept of justice? If so, does he distance himself from the tradition, represented here by Thomas Aquinas? Finally, it is a matter of investigating whether there is one, and only one, Spinoza concept of justice.

KEYWORDS: Spinoza; Thomas Aquinas; reconceptualization; justice; city.

\section{Nariz de cera}

Uma das agudezas de Espinosa consiste em fazer uso de termos da tradição e dar a eles novas cores, subvertendo-os. Uma reconceitualização, como defende um agudo comentador ${ }^{2}$. De fato, Deus, conceito-chave de seu sistema, veio a ser natureza ou substância (ESPINOSA, 2015, pp. 30-121) ${ }^{3}$. Não, portanto, simples, eterno, invariável, ato puro, transcendente, como em São Tomás de Aquino (AQUINO, 2017, pp. 59-88), mas imanente. Direito, por seu turno, passou a ser potência, derivado da potência absoluta, ou seja, derivado da potência da substância ou natureza. O que, importa sublinhar, estiola por completo a divisão estanque direito natural versus direito positivo, visto que todo direito é por definição potência, sendo, por esta razão, o direito natural em estado de natureza mera opinião ${ }^{4}$, como afirma no Tratado político (ESPINOSA, 2009, p. 19 - TP II 15). O mesmo se dá com o conceito de liberdade, pensada não como livre-arbítrio, livre escolha entre possíveis, mas como decorrência de afetos alegres, passivos ou ativos, experienciados pelos homens e, no caso dos afetos alegres ativos, como ações no interior da necessidade causal da substância. A liberdade política, por sua vez, será o exercício do desejo-potência na cidade, uma vivência, por parte do súdito-cidadão, de afetos alegres em maior frequência no interior do corpo político. E a liberdade do sábio - tema que

\footnotetext{
${ }^{2}$ Sobre a reconceitualização de termos da tradição e do senso comum por Espinosa, ver: CAMPOS, 2008, pp. 17 e 18. Relevante dizer que, para Campos, alguns estudiosos de Espinosa veem aí não uma reconceitualização de termos da tradição, mas uma ambiguidade terminológica. Entendo, no mesmo sentido de Campos e de outros comentadores, que a tese da ambiguidade terminológica em Espinosa não se sustenta, havendo, isto sim, reconfiguração de sentidos dos termos usados pelo autor, os quais são colhidos, é claro, do vocabulário da tradição à qual o autor pertence. São, entretanto, colhidos e ressignificados, e este é o ponto fundamental.

${ }^{3}$ As obras de Espinosa que serão mencionadas se encontram na edição crítica de Carl Gebhardt, citada nas referências bibliográficas. As traduções consultadas são as seguintes: ESPINOSA, 2015 [Ética]. ESPINOSA, 2009 [Tratado Político]. ESPINOSA, 2003 [Tratado Teológico político]. ESPINOSA, 2014 [Correspondência]. Para a E e o TP, usar-se-á a seguinte abreviação: para a Ética, E, seguido da parte em romano, D para definições, Def af para definição dos afetos, A para axiomas, Dem para demonstrações, P para proposições, Cor para corolários, Ap para apêndices, L para lemas, Esc para escólios, Post para postulados, Explic para explicações. Um numeral arábico indicará o número de cada um desses itens. Para o TP, numeral romano indica o capítulo e numeral arábico indica o parágrafo. Para o TTP, numeral romano indica o capítulo. Para a Correspondência, Ep, com numeração em arábico. Assim se procede para facilitar a consulta a qualquer edição das obras de Espinosa, mesmo que seja à custa do não cumprimento estrito das regras deste periódico e da ABNT. Cumpre-se, entretanto, o espírito das regras.

${ }^{4}$ Sobre esta questão, ver: GUIMARAENS e ROCHA, 2014, p. 191. Afirmam os autores: "Para Spinoza, o direito natural no estado de natureza permanece separado das condições que permitem sua realização e seria uma hipótese cuja validade só tem sentido abstrato (no sentido spinozano do vocábulo, como algo que é pensado separado de suas causas)."
} 
sequer definirei aqui, em razão de sua complexidade - será algo de mais raro alcance, como exposto na parte $\mathrm{V}$ da Ética. O mesmo ocorre com a questão dos afetos, na verdade variações de potência dos indivíduos humanos para mais ou para menos (alegria e tristeza, respectivamente). E, ponto fundamental, não conceituados por Espinosa como vícios. Assim, não devem ser vituperados, mas compreendidos, por serem naturais. Os exemplos poderiam se estender.

O objetivo do artigo é tratar precisamente de um conceito menos pesquisado pelos comentadores, mas que, hipótese que será defendida, é igualmente reconceitualizado por Espinosa. Trata-se do conceito de justiça. Intenta-se lançar algumas notas sobre o tema, sem a pretensão de esgotá-lo. Notas, para ser mais preciso, que almejam esboçar uma hipótese acerca do conceito que Espinosa dá ao termo justiça e seus derivados - cidade justa, lei justa, homem justo etc.

Procurarei pinçar, em primeiro movimento, o conceito em São Tomás de Aquino, para, por contraste, explicitar em quê Espinosa inova em face da tradição. Faço este movimento para propor com mais clareza o conceito de justiça espinosano, que me parece uno, ou seja, Espinosa não teria vários conceitos de justo no correr da obra ${ }^{5}$, mas apenas um, o qual se apresenta na parte IV da Ética, especificamente no escólio 2 da Proposição 37. Além disso, é este o conceito espinosano em todo o corpus, sendo que quando Espinosa faz uso de outra definição, o faz como não sendo a sua.

Por esta razão, o escólio 2 da Proposição 37 da Parte IV da Ética será mais explicitamente tratado, mas sempre à luz do sistema espinosano. Isso implica que o corpus, em algumas de suas partes, será movimentado para lançar luz neste trecho importante da obra, por tratar explicitamente e desdobradamente do tema que aqui se quer compreender.

A questão-chave, que norteará o ensaio, é a seguinte: Espinosa possui um conceito de justiça? Se sim, e os textos indicam que sim, ele se distancia da tradição, aqui representada e sintetizada por São Tomás de Aquino? Caso se distancie, em que termos isto se dá? Em outras palavras, após traçar os movimentos mais essenciais do conceito tomasiano, o intuito é propor um conceito de justiça em Espinosa e levantar a hipótese de que se trata de conceito único no corpus.

São Tomás de Aquino é movimentado no ensaio em viés acentuadamente metodológico. Com efeito, o doutor angélico trata da questão da justiça abundantemente e com alto grau de

\footnotetext{
${ }^{5}$ Defende esta tese Campos, 2016
} 
minúcia e refinamento ${ }^{6}$. A parte do corpus tomasiano que interessa aqui, entretanto, para aclarar a concepção espinosana, é precisamente a dos momentos em que o autor fixa o conceito de justiça usando os mesmos termos e teses de uma tradição que se alonga no passado (Aristóteles, Ulpiano, Justiniano e Aquino), termos estes que são citados por Espinosa praticamente ipsis litteris. Dessa maneira, se as expressões são quase as mesmas, em quê Espinosa inova? Não teriam, ambos, a mesma posição?

\section{Contraponto metodológico: notas sobre a justiça em São Tomás de Aquino}

São Tomás de Aquino (século XIII) conceitua justiça na mesma linha de Ulpiano (séc. II para III d.c.) e Justiniano (séc. V para VI d.c.), ou seja, faz uso do conceito tal qual expresso no Corpus Iuris Civilis ou Digesto, do imperador Justiniano [D, 1, 1,10]

10. Ulpiano, Regras, Livro 1: Justiça é a vontade constante e perpétua de atribuir a cada um o que é seu. § I. Estes são os preceitos do direito: viver honestamente, não causar dano a outrem e dar a cada um o que é seu. § II. Jurisprudência é o conhecimento das coisas divinas e humanas, e conhecimento do que é justo e injusto.

[10. ULPIANUS libra I. Regularum: lustitia estconstans et perpetua voluntas ius suum cuique tribuendi. $\S$ I. - Juris praecepta sunt haec: honeste vivere, alterum non laedere, suum cuique tribuere. $\S 2$. Iurisprudentia est divinarum atque humanarum rerum notitia, iusti atque iniusti scientia.]

Mostro, a seguir, como esta clássica definição de justiça é interpretada por São Tomás de Aquino.

Eis o primeiro movimento da Suma Teológica, na q. 58, ao tratar do tema da Justiça: trata-se de verificar, segundo Tomás, se a tese dos jurisconsultos sobre a natureza da justiça é correta. Tal tese afirma: iustitia est constans et perpetua voluntas ius suum unicuique tribuens [justiça é a vontade constante e perpétua de dar a cada um o que é seu]. (AQUINO, 2012, p. 55 - II IIae, q. 58) ${ }^{8}$.

Após seis objeções, traço típico do método da Suma Teológica, das quais não tratarei aqui, Tomás de Aquino afirma a correção da tese. O argumento é o que segue e, como se verá, não remontará apenas a Ulpiano e à sua clássica definição de justo, mas a Aristóteles. Portanto, ao século IV a.c. Há, assim, ao menos na proposta tomasiana, uma linha vermelha que alinhava o estagirita (séc. IV a.c.) a Ulpiano (séc. II para III d.c.), a Justiniano (séc. V para VI d.c.) e, por fim, ao próprio Tomás de Aquino (séc. XIII d.c.), quanto ao conceito de justiça.

\footnotetext{
${ }^{6}$ Aquino trata longamente do tema da Justiça, na Suma Teológica, em: AQUINO, 2012, pp. 45-276 - ST, II a IIae, q. 57 a q. 80 .

${ }^{7}$ Cotejei duas traduções, uma em inglês e outra em português, com o original latino: JUSTINIAN, 1998 e JUSTINIANO, 2010. Justiniano cita, nesta famosa passagem, as Regras, de Ulpiano, no momento em que este define justiça.

${ }^{8}$ Uso a edição citada ao final, da Loyola, bilíngue.
} 
Afirma o autor que a definição "justiça como vontade constante e perpétua de dar a cada um o seu direito [ou "a cada um o que é seu", em outra versão]" é completa. Por que o seria? Escreve:

\begin{abstract}
Por isso, na definição da justiça, menciona-se primeiro a vontade, para mostrar que o ato de justiça deve ser voluntário. Ajunta-se, porém, a constância e a perpetuidade, para indicar a firmeza do ato. Assim, pois, a referida definição da justiça é completa, a não ser que se tome o ato pelo hábitus, que é especificado pelo ato, já que o hábitus se ordena ao ato. Para dar a essa definição sua devida forma, bastaria dizer: "A justiça é o hábitus, pelo qual, com vontade constante e perpétua, se dá a cada um o seu direito [se dá a cada um o que é seu]" - Essa definição é quase idêntica à que Aristóteles enuncia: "a justiça é o hábitus que leva alguém a agir segundo a escolha que faz do que é justo." (AQUINO, 2012, p. 56 - q. 58, art. 1).
\end{abstract}

Há 12 artigos sobre o tema da justiça na questão 58 da Suma Teológica. No artigo 1, Aquino dá o conceito e a natureza da justiça, como visto acima. No $11^{\circ}$, trará à discussão novamente a questão que interessa a este ensaio - pois Espinosa a retoma usando quase os mesmos termos - e que já aparecera no artigo $1^{\circ}$ : o ato da justiça consiste em dar a cada um o que é seu? [Utrum actus iustitiae sit reddere unicuique quod suum est].

A resposta terá como principal argumento a tese de que se dá a cada um o que lhe é proporcional de acordo com o que é justo. Escreve:

Como ficou dito, a matéria da justiça é a ação exterior, enquanto ela mesma, ou o objeto que por ela utilizamos, estão proporcionados a uma outra pessoa, com quem a justiça nos coloca em relação. Ora, a cada pessoa diz-se pertencer como seu, aquilo que lhe é devido por uma igualdade proporcional. Por isso, o ato de justiça consiste precisamente em dar a cada um o que é seu. (AQUINO, 2012, p. 74).

O "como ficou dito", do excerto acima, está no artigo 8:

E uma vez que a justiça tem por objeto as relações com outrem, ela não abarca toda a matéria da virtude moral, mas somente as ações e coisas exteriores, sob o ângulo especial de um objeto, a saber, enquanto por elas um homem é colocado em relação com outro. (AQUINO, 2012, p. 69).

A conclusão a que se pode chegar, pelos excertos acima expostos, é a de que São Tomás de Aquino toma as definições de Ulpiano, citadas no Digesto de Justiniano, e delas se apropria, as faz suas. Porém, no estilo alto de sua filosofia, com extremo refinamento conceitual, desdobra o conceito em suas minúcias e o liga a Aristóteles, fazendo de sua posição um fio que une a tradição grega, de viés aristotélico, à tradição romana. O adendo tomasiano é a análise exaustiva do conceito, mostrando suas nuances e desdobrando os conceitos de voluntariedade, constância, perpetuidade, dar a cada um o que lhe pertence, bem como a tese de que a justiça é a ação exterior em face de alguém com quem se tem uma relação e a quem se deve algo. Em suma: vontade constante e perpétua de dar a cada um o que é seu.

\footnotetext{
9 "quod iustitia est habitus secundum quem aliquis constanti et perpetua voluntate ius suum unicuique tribuit. - Et quasi est eadem definitio cum ea quam Philosophus ponit, in V Ethic., dicens quod iustitia est habitus secundum quem aliquis dicitur operativus secundum electionem iusti."
} 
Todavia, o que é o seu de cada um? Ora, o direito é o objeto da justiça (AQUINO, 2012, p.46 - ST, IIa IIae, q. 57, art. 1). O seu de cada um é o que o direito assim estabelece, responderia esta tradição. O direito é a lei? Diz Aquino: “A lei não é propriamente o direito, mas a regra do direito" (AQUINO, 2012, p. 47 - ST, IIa IIae, q. 57, art. 1). A lei é o parâmetro para que se saiba ao certo o que é o seu de cada um. O que garante, entretanto, que a lei estabelece o parâmetro adequado da justa proporção, o seu de cada um? Espinosa, como mostrarei a seguir, traz elementos para a resposta. Não casualmente, usa os mesmos termos da tradição. Porém, reconfigurados pelo seu sistema de maneira que há o justo apenas e tão somente segundo a lei positivada, é certo, ou seja, segundo o direito civil. Todavia, não é qualquer direito civil que configura o justo, pois há limites ao poder. Limites ontológicos, naturais, afetivos. Diferentemente da tradição tomasiana, que fará uso do conceito de lei divina como parâmetro último (vinda de um Deus transcendente à criação) (AQUINO, 2010, pp. 528-541 - ST, Ia IIae q. 91), a reconceitualização proposta por Espinosa buscará o fundamento na imanência, pois o que há é apenas a substância única, causa imanente do real. Em São Tomás, mais especificamente quanto a este ponto do parâmetro último, importa sublinhar, para que se explicite o contraste em face de Espinosa, que há no limite uma lei eterna, uma razão suprema. Afirma Aquino: "Suposto, porém, que o mundo seja regido pela providência divina, como se mostrou na I Parte, é manifesto que toda a comunidade do universo é governada pela razão divina. E assim a própria razão do governo das coisas em Deus, como existindo no príncipe do universo, tem razão de lei.” (AQUINO, 2010, p. 529 - ST Ia IIae q. 91, art. $1^{\circ}$ ). A lei emanada do príncipe do universo, Deus, é o padrão do seu de cada um, em última análise ${ }^{10}$.

A justiça, para Espinosa, por outro lado, surgirá com o direito civil posto, e apenas neste momento. O direito civil é o que define o seu de cada um. Porém, se não existe transcendência e razão suprema a amparar o conceito terreno de lei e de justiça, há um campo de forças, um campo afetivo, a definir os limites ontológicos da lei, fora dos quais o justo deixa de ser o direito civil, a lei positivada ${ }^{11}$, e passa a ser o direito de guerra, pois o pacto, a tensão de forças entre soberano e multidão, já não mais se justifica. É o fim da cidade como instância garantidora do justo, nesse sentido ontológico, isto é, da garantia de uma vida digna, que não se confunde com a circulação de sangue, mas se identifica à fortaleza de ânimo dos cidadãos que a constituem (ESPINOSA, 2009, pp. 44-45 - TP V 4-5). Este o ponto que tratarei em pormenor a seguir, no sentido de levantar a hipótese de que há um, e apenas um, conceito de justiça em Espinosa,

\footnotetext{
${ }^{10}$ Nesse sentido, ver: BITTAR, 1998, p. 346.

${ }^{11}$ Espinosa usa o termo direito civil.
} 
ainda que ele use, no correr da obra, outros sentidos, os quais, segundo esta hipótese, são conceitos alheios, não o seu.

\section{Justiça em Espinosa: a reconceitualização}

Proponho, a seguir, uma análise do Escólio 2 da Proposição 37 da parte IV da Ética (E IV P 37 Esc). Espinosa cumpre, neste momento do texto, o que havia prometido no Apêndice da Primeira parte. Assim, anunciando a promessa de deslinde da questão, inicia o escólio 2 da referida Proposição.

Entretanto, faz breve recuo antes de adentrar a questão do justo e do injusto. Recuo necessário, uma vez que não se compreenderia o conceito de justiça sem esse passo atrás. Em que consiste o recuo? Consiste em tratar de dois temas-requisito, a saber, o estado natural e o estado civil do homem. Espinosa inicia, como se verá a seguir, o movimento do escólio com uma tese ontológica, ligada à política e ao conceito de justo e de direito.

Escreve que "Cada um existe por sumo direito de natureza" (ESPINOSA, 2015, p. 435 - E IV P 37 Esc). É por este direito que cada um age, e assim o faz de acordo com a necessidade da sua natureza. Vale ressaltar que para Espinosa direito equivale a potência (ESPINOSA, 2009, p. 12 - TP II 4). Esse um ponto fundamental, e que diferenciará Espinosa da tradição jusnaturalista de viés essencialista (DELEUZE, 2009, pp. 89-90; GUIMARAENS e ROCHA, 2014, p. 194), bem como possibilitará que em seu sistema filosófico haja uma ponte entre ontologia, direito e política. Volto ao fio do raciocínio do escólio. Por consequência, é por tal direito que cada um (1) julga o que é bom e o que é mau; (2) Cuida do que tem utilidade a si de acordo com seu engenho; (3) vinga-se; (4) se esforça para conservar o que ama e destruir o que odeia.

Palavras fortes, do campo natural, do campo da potência. O fundamento da questão é sem sombra de dúvida ontológico. Julgar, cuidar do que é útil, vingar-se, esforçar-se para destruir o que odeia e conservar o que ama decorrem, no limite, da tese colocada já no segundo parágrafo do escólio, segundo a qual "Cada um existe por sumo direito de natureza" (ESPINOSA, 2015, p. 435 - E IV P 37 Esc). Com efeito, os homens são modificações da potência absoluta da substância, ou seja, Deus ou a natureza. Esta tese, por sua vez, se funda na parte I da Ética, cujo tema é o conceito de Deus (sinônimo de natureza ou substância) (ESPINOSA, 2015, pp. 39-121).

Após este primeiro movimento de raciocínio, o autor lança uma tese já apresentada em E IV P 35 Cor 1 (ESPINOSA, 2015, p. 427), a saber, se os homens vivessem sob a conduta da 
razão, cada qual possuiria este direito sem dano a outrem. A razão, com efeito, equilibraria as disputas nos seus corretos limites, fazendo com que a política fosse desnecessária.

Porém, a realidade efetiva da coisa é outra, para usar os termos de Maquiavel (MAQUIAVEL, 2011, p. 151), a quem Espinosa chamou agudíssimo e prudentíssimo (ESPINOSA, 2009, p. 46 - TP V 7) ${ }^{12}$. Os homens vivem sob a conduta dos afetos e estes os arrastam "em direções diversas" (ESPINOSA, 2015, p. 435), o que os faz contrários uns aos outros quando precisamente necessitam de auxílio mútuo.

A vida sob a conduta da razão é alcançável, mas rara. O frequente, o cotidiano, o comezinho é a conduta sob afetos contrários no momento mesmo em que os homens necessitariam de mútuo auxílio. Como resolver a questão fática? Não, certamente, dada a imanência e dada a ontologia, que faz dos homens o que são e não o que os filósofos gostariam que eles fossem, qualquer modelo ou utopia. Essa a tese que se apresenta no início do Tratado Político. Quem pensou em forjar a cidade a partir de modelos, diz o autor, ou fez sátira, ou fez utopia (ESPINOSA, 2009, pp. 05-06 - TP I 1). A saída deve ser outra. Pelo trilho dos afetos, que trazem a possibilidade de acordos de fundo. Isto é, por uma espécie de "astúcia da razão" que dá liga à concórdia (CHAUI, 2011, p. 182) ${ }^{13}$.

A saída é que os homens "cedam o seu direito natural" [necesse est, ut jure suo naturali cedant] (ESPINOSA, 2015, pp. 435-437) e "tornem uns aos outros seguros de que nada haverão de fazer que possa causar dano a outro.” (p. 437). O caminho é afetivo. E não poderia ser diferente, dada a ontologia da potência e a definição dos homens como afetivos e potentes. Por isso o que fundamenta esta tese, no movimento argumentativo do corolário ora em análise, é E III P 39 e E IV P 7 (ESPINOSA, 2015, p. 297 e 389). Afetos somente podem ser coibidos por afetos, contrários e mais fortes, bem como cada qual deixa de causar dano a outrem por temor de um dano maior.

\footnotetext{
${ }^{12}$ Para uma comparação entre ambos e sobre a presença tácita e explícita de Maquiavel em Espinosa, ver MONTANS BRAGA, 2019. Parece haver mais Espinosa tácito e espraiado pela obra do que as parcas citações explícitas e elogiosas. Maquiavel é autor que foi recuperado por vários filósofos posteriores. Muitos não o citam explicitamente, talvez em razão de sua má fama, ainda que o usem nas entrelinhas de seus escritos. Para uma discussão sobre a recepção de Maquiavel por vários autores ao longo da história das ideias, ver VALVERDE, 2019. Para uma discussão sobre as presenças tácitas de Maquiavel na obra de David Hume, ver REIS, 2019.

${ }^{13}$ CHAUI, 2011, pp. 173-191. Afirma a autora sobre o que permite a passagem do medo à esperança: "O que permite essa passagem de uma paixão à sua contrária é, de um lado, sob a lei do mal menor e do bem maior, a vitória afetiva da esperança, paixão de alegria, cuja força é superior e contrária à do medo, paixão da tristeza; e, de outro, o fato de que o que reforça a esperança, mesmo que ela não o saiba, são as noções comuns da razão, visto que estas são o fundamento ontológico da convenientia e, portanto, a mola racional invisível da cooperação entre humanos" (p. 182). E conclui: "Poderíamos até mesmo falar numa 'astúcia da razão', que se serve de uma paixão, a esperança, para dar força operante à potência racional das noções comuns" (p. 182).
} 
Espinosa, com efeito, já estabelecera no axioma 1 da parte IV da Ética o seguinte: "Na natureza das coisas, não é dada nenhuma coisa singular tal que não se dê outra mais potente e mais forte do que ela. Mas, dada uma coisa qualquer, é dada uma outra mais potente pela qual aquela pode ser destruída.” (ESPINOSA, 2015, p. 381). Espinosa quer explicitar, nesta passagem, que as coisas singulares, e entre elas os indivíduos humanos, são potências que estão necessariamente submetidas a potências mais fortes. O poder soberano da cidade, neste caso, será uma potência mais forte a favor da existência das potências individuais, possibilitadora, por assim dizer, de um exercício digno da potência individual de cada súdito-cidadão. Mas deixo este ponto em espera para dar seguimento ao movimento argumentativo.

E diz Espinosa, como conclusão da argumentação, que "É portanto por esta lei que a Sociedade poderá firmar-se" (p. 437). Como? Reivindicando para si o direito - leia-se, a potência - que cada qual tem de vingar-se e de julgar sobre o bem e o mal. Em suma, que tenha o poder de preservar uma regra comum de vida.

Ora, viu-se logo antes que o direito de cada um consiste precisamente nisso: (1) julgar o que é bom e o que é mau; (2) cuidar do que tem utilidade a si de acordo com seu engenho; (3) vingar-se; (4) se esforçar para conservar o que ama e destruir o que odeia.

A Sociedade que reivindica para si esta potência, este direito, faz tais leis, regras comuns de vida, não pela razão, mas impondo ameaças. É esta Sociedade que Espinosa denomina Cidade. Aquela que se firma "pelas leis e pelo poder de se conservar" (ESPINOSA, 2015, p. 437). Os indivíduos que são defendidos pelo direito desta Sociedade, desta Civitas, são chamados cidadãos (p. 437).

Veja-se que não se trata de estar sob a Civitas, apenas. Trata-se de ser defendido pelo direito que ela tem, cujo fundamento é afetivo, é potência cedida pelos cidadãos. Porém, não por um contrato, não pela razão, mas pelo medo de um mal maior - a morte, o dano etc.

Pois bem, apenas após este longo raciocínio Espinosa chega ao conceito de justo e injusto. $\mathrm{O}$ justo é a obediência à lei da cidade. $\mathrm{O}$ injusto, a desobediência à lei da cidade. Afirma Espinosa, para distanciar este estado do estado natural:

\footnotetext{
Ademais, no estado natural ninguém é Senhor de coisa alguma por consenso comum [expressão já usada anteriormente; por consenso comum da cidade é que se discerne o bom e o mau], nem na Natureza é dado algo que possa ser dito deste homem e não daquele, mas tudo é de todos; e por isso no estado natural não pode ser concebida nenhuma vontade de atribuir a cada um o que é seu ou de arrancar de alguém o que é

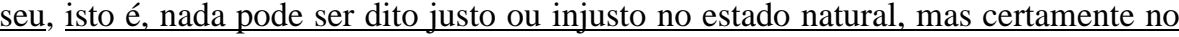
estado civil, onde o que é deste ou daquele é discernido pelo consenso comum. (ESPINOSA, 2015, pp. 437-439 - E IV P 37 Esc 2 - grifo meu).
} 
Ora, em quê Espinosa difere do clássico conceito, "vontade constante e perpétua de dar a cada um o que é seu" como definição da justiça? A diferença seria apenas a de que Espinosa não usa os termos "perpétua" e "constante", os quais Aquino declara como fundamentais para que a definição de justiça possa ser considerada completa? (AQUINO, 2012, p. 56 - q. 58, art. 1). Não parece ser esta a única diferença.

Ao que indicam os fundamentos do conceito de Civitas, novamente Espinosa os reelabora de modo a lhes dar os mesmos nomes que foram dados pela tradição, porém, sentidos diversos, os quais apenas ganham inteligibilidade no sistema espinosano. Este um aspecto da hipótese que gostaria de lançar. A definição é muito próxima da tradição referida por São Tomás de Aquino, que alinhava ao menos quatro autores desde Aristóteles até ele mesmo. Trata-se das mesmas palavras, quase as mesmas definições da tradição - "vontade de atribuir a cada um o que é seu" (ESPINOSA, 2015, pp. 437-439 - E IV P 37 Esc 2). Entretanto, no universo conceitual espinosano, não se pode interpretar tais termos com as mesmas lentes da tradição. É preciso que se submeta a definição aos vários ajustes conceituais propostos por Espinosa conflito entre potências, direito de natureza da substância única, direito de natureza das coisas singulares, estas como parte e modificação da substância, direito como idêntico a potência etc. Sem o pano de fundo das reconceitualizações, nada se apreende das inovações propostas no escólio quanto ao conceito de justiça. Veja-se que Espinosa usa a expressão para se referir ao estado natural e o contrapor ao civil, no qual há justo e injusto: Ele diz:

[...] e por isso no estado natural não pode ser concebida nenhuma vontade de atribuir a cada um o que é seu, isto é, nada pode ser dito justo ou injusto no estado natural, mas certamente no estado civil, onde o que é deste ou daquele é discernido pelo consenso comum (ESPINOSA, 2015, pp. 437-439 - E IV P 37 Esc 2).

A lei que a cidade dá aos cidadãos lhes é outorgada para os proteger. O Tratado Político é claro quanto a isso ao estabelecer: “[...] o estado civil é naturalmente instituído para eliminar o medo comum e afastar as comuns misérias [...]" (ESPINOSA, 2009, p. 28 - TP III 6). E a lei da Civitas vem do consenso comum. O consenso comum, dados os argumentos até aqui levantados, não é uma abstração, um ideal a ser alcançado ou a partir do qual se define o justo do direito civil. Nada há sem causa em uma filosofia da imanência como a espinosana. Parece ser, o consenso comum, uma tensão entre potências que se dá no campo afetivo, entre o poder soberano e os súditos-cidadãos. Certa quantidade de potência é cedida constantemente pela multidão (os homens como potências individuais dispersas) a uma instância, o poder soberano, que detém o estado (imperium) por ter a incumbência da república, ou seja, a de estatuir, interpretar e abolir direitos, decidir sobre a guerra e a paz etc. Quem detém o estado, que Espinosa chama de imperium, definido pela potência da multidão, tem a incumbência da 
república (ESPINOSA, 2009, p. 20 - TP II 17). Essa tensão entre potências, constantemente constituída, é a Sociedade ou Civitas. O poder soberano instituído, pela transferência constante de um campo afetivo de forças, cria o direito civil, o executa e interpreta (ESPINOSA, 2009, p. 20 - TP II 17).

O consenso comum é, pois, esta continuidade do acordo afetivo em razão de os súditoscidadãos terem a garantia da vida com fortaleza de ânimo, razão ontológica da instituição da cidade. O que implica que há os limites definidos no Tratado Político ao poder do soberano. A lei não pode definir tudo aquilo que queira o poder soberano. Não se pode mandar que se ame a quem se odeia ou se odeie a quem se ama. Não se pode ordenar que uma mesa coma erva (ESPINOSA, 2009, p. 29 - TP III 8), nem se pode legislar sobre a liberdade de pensamento ou forçar que o homem ceda a faculdade de julgar (ESPINOSA, 2003, pp. 300-310 - TTP XX; ESPINOSA, 2009, p. 29 - TP III 8). Trabalho este ponto a seguir, mostrando como ele se articula com o conceito de dar a cada um o que é seu e ao que é o seu de cada um.

Os limites ao poder soberano, que detém a Civitas, podem ser resumidos em um raciocínio, que desdobro a seguir: a razão da instituição e manutenção da cidade é a garantia da potência individual dos cidadãos (seu direito natural), aquilo que Espinosa chama de fortaleza de ânimo, para se contrapor ao viver como ovelhas ou ao conceito de cidade como sinônimo de solidão (ESPINOSA, 2009, pp. 44-45 - TP V 4).

Esses limites dão o tom do que pode ser enquadrado dentro de um direito civil definidor da justiça. O "dar a cada um o que é seu” espinosano, em função da imanência da substâncianatureza e de todo o arcabouço conceitual do corpus, demanda que o direito civil seja função afetiva da razão pela qual foi criado. Não é qualquer direito civil que poderá ser considerado um direito justo, mas apenas aquele que garanta a efetividade, nos homens, da fortaleza de ânimo como vivência preponderante no interior do corpo político (ESPINOSA, 2009, p. 45 TP V 5) ${ }^{14}$

Daí que não esteja nas mãos da cidade (e do poder soberano que detém o estado ou imperium), por quaisquer recompensas ou ameaças, que se requeira a um homem que este ame quem odeia ou odeie a quem ama. Nesse mesmo sentido, diz Espinosa, não se podem requerer coisas que a natureza humana "abomina a tal ponto que as tem por piores que qualquer mal,

\footnotetext{
${ }^{14}$ Sintetizam muito bem este ponto, levantando a questão da multidão como instituidora do direito do imperium [estado ou Estado], GUIMARAENS e ROCHA, 2014: "A partir do que se expôs, é possível tornar nítido o que Spinoza entende por 'conservar o direito natural'. Se a potência da multidão determina o direito do Estado, é o direito natural da multidão a medida do direito civil. Spinoza conserva o direito natural porque a potência da multidão, seu direito natural, é causa do direito do Estado ou, como dizem os juristas, do direito positivo. Inclusive, é sempre bom lembrar que, tendo em vista o sentido da causalidade na obra de Spinoza, trata-se de causa eficiente imanente, uma causa que não se afasta jamais de seus efeitos.” (p. 196).
} 
como seja, o homem testemunhar contra si mesmo, torturar-se, matar os seus pais, não se esforçar por evitar a morte, e coisas semelhantes a que ninguém pode ser induzido [...]" (ESPINOSA, 2009, p. 29 - TP III 8). De fato, uma lei civil com este conteúdo esbarra na natureza das coisas e dos homens. Trata-se de um tipo de lei civil, definidora do "justo", que leva a que a natureza humana a abomine, pois o afeto é algo da natureza, não um dever-ser moral, no sistema espinosano. Uma lei com este conteúdo é tão inútil quanto perigosa, e contribui para que a cidade tenda ao seu esfacelamento institucional na medida em que propõe algo que causa na natureza abominação. Não se pode ordenar que uma mesa coma erva, por se tratar de algo impossível no mundo natural (ESPINOSA, 2009, p. 39 - TP IV 4). Não se pode legislar sobre a liberdade de pensamento (ESPINOSA, 2003, pp. 300-310 -TTP XX), pela mesma razão. Outros pontos são levantados e desdobrados pelo autor no Tratado Político (ESPINOSA, 2009, pp. 38-39 - TP IV 4). Em síntese, aqueles objetos de legislação que a natureza humana abomina e que, portanto, vão de encontro à razão de ser da Civitas, podendo destruí-la, são sumariados na seguinte passagem do Político:

[...] deve também ter-se em conta que os súditos não estão sob jurisdição de si próprios mas da cidade [ou seja, o "dar a cada um o que é seu" depende da cidade e de seu direito civil], na medida em que receiam a sua potência ou as suas ameaças, ou na medida em que amam o estado civil (pelo art. 10 do cap. ant). Donde se segue que tudo aquilo que ninguém pode ser induzido, por recompensas ou ameaças, a fazer não pertence aos direitos da cidade (ESPINOSA, 2009, p. 29 - TP III 8).

Por esta razão, o poder soberano da cidade, esteja ele em mãos de um rei, de uma aristocracia ou de um conselho democrático, aberto à participação de todos os cidadãos ${ }^{15}$, deve atentar ao afeto inimigo da Civitas, a saber, a indignação. Não tratarei em pormenor do tema, o qual já trabalhei em outros textos ${ }^{16}$, mas apenas chamo a atenção para o que concerne ao tema da justiça. A lei da cidade não deve, sob pena de ameaçar a existência do corpo político, gerar a indignação como afeto preponderante nos súditos-cidadãos. Quando isso ocorre, o poder soberano, detentor da cidade, perde potência em face dos próprios cidadãos. Perde, por assim dizer, eficácia, pois a indignação espelhada entre os cidadãos, por um mal causado pelo poder soberano a grande quantidade de pessoas, pode fazer com que as ameaças da lei não mais tenham efeito para direcionar os cidadãos (ESPINOSA, 2009, p. 30 - TP III 8). De fato, quando a cidade oferece motivos para que vários conspirem - o que pode se dar em razão do afeto

\footnotetext{
${ }^{15}$ Sobre os cidadãos que podem participar e votar no conselho supremo, bem como aceder a cargos públicos, em um imperium democrático, ver o último capítulo, XI, incompleto, do Político, onde se coloca outrossim a polêmica exclusão das mulheres desses direitos e as razões que Espinosa explicita para tal.

${ }^{16}$ Sobre o tema, ver, entre outros: MONTANS BRAGA, 2018, pp. 1037-1051.
} 
indignação, espraiado nos cidadãos por algum motivo causado pela cidade mesma, isto é, pelo poder soberano -, ela perde potência, perde direito.

A indignação, com efeito, é “[...] o Ódio a alguém que fez mal a outro.” (ESPINOSA, 2015, p. 349 - E III Def af 20). Quando o soberano edita leis cujo conteúdo gera a indignação, é certo que perde potência e flerta com o risco de destruir a cidade. Assim, Espinosa escreve que "Há certamente coisas que a cidade deve ter medo, e da mesma forma que cada cidadão ou cada homem no estado natural, assim também a cidade está tanto menos sob jurisdição de si própria [perde direito, pois perde potência] quanto maior é o motivo que tem para temer" (ESPINOSA, 2009, pp. 30-31 - TP III 9). No equilíbrio de potências entre súditos-cidadãos, de um lado, e poder soberano, do outro, leis emanadas deste último, cujo conteúdo queiram induzir a comportamentos que abominam à natureza humana, trazem como efeito a perda de direitopotência deste mesmo poder soberano. Ou seja, podem levar a cidade ao seu fim.

Do mesmo modo, produz o mesmo perigo à cidade o comportamento de membros do poder soberano (ESPINOSA, 2009, p. 39 - TP IV) que levem ao mesmo efeito de leis cujo conteúdo abomina à natureza humana. Por exemplo, nas palavras de Espinosa, “[...] para aqueles ou aquele que detém o estado [imperium], é tão impossível correr ébrio ou nu com rameiras pelas praças, fazer de palhaço, violar ou desprezar abertamente as leis por ele próprio ditadas e, com isso, conservar a majestade, como é impossível ser e não ser ao mesmo tempo." (ESPINOSA, 2009, p. 39 - TP IV 4).

Por isso a justiça, em Espinosa, é o "dar a cada um o que é seu” de acordo com o que institui o direito civil da Civitas, como apresentado na Ética (ESPINOSA, 2015, pp. 435-439 E IV P 37 Esc 2). Mantém o filósofo, portanto, quase as mesmas palavras da tradição sintetizada por São Tomás de Aquino. Porém, o conteúdo das leis, assim como o que os membros do poder soberano podem fazer, tudo isso, não pode abominar à natureza humana, sob pena de o direito civil vir a ser direito de guerra, momento mesmo em que a cidade perdeu sua função e o "contrato" não mais se justifica. Talvez por isso Espinosa não use em sua definição de justiça os seguintes termos presentes na definição de São Tomás de Aquino: "constante" e "perpétua". Em razão do pano de fundo espinosano acima analisado, o qual lança luz em seu conceito de justiça, estes termos não têm função.

Apenas para pontuar esta questão do direito civil que devém direito de guerra, a qual já desenvolvi em outros textos ${ }^{17}$, faço duas ou três colocações a seguir. O direito de guerra é uma espécie de volta ao estado de natureza em razão do estiolamento da potência do poder soberano,

${ }^{17}$ Ver, entre outros: MONTANS BRAGA, 2017. 
pelas razões vistas acima. Espinosa escreve explicitamente sobre o tema em um parágrafo repleto de filigranas e denso em conceitos. Ele afirma:

\begin{abstract}
O contrato, ou as leis pelas quais a multidão transfere o seu direito para um só conselho ou para um só homem devem, sem dúvida, ser violadas quando interessa à salvação comum violá-las. Mas o juízo acerca deste assunto, ou seja, se interessa à salvação comum violá-los, ou outra coisa, nenhum privado o pode fazer por direito [...]; só aquele que detém o estado. [...] Se, contudo, elas são de natureza tal que não podem ser violadas sem que ao mesmo tempo se debilite a robustez da cidade, isto é, sem que ao mesmo tempo o medo comum da maioria dos cidadãos se converta em indignação, a cidade, por isso mesmo, dissolve-se e cessa o contrato, o qual, por conseguinte, não é defendido pelo direito civil mas pelo direito de guerra. E, portanto, aquele que detém o estado [ou seja, aquele que, por consenso comum, detém a incumbência da república, o poder soberano (ESPINOSA, 2009, p. 20 - TP II 17) ${ }^{18}$ ] também não tem de observar as condições deste contrato por nenhuma outra causa a não ser aquela porque o homem no estado natural, para não ser seu inimigo, tem de precaver-se para que não se mate a si mesmo [...] (ESPINOSA, 2009, p. 40-41 - TP IV 6).
\end{abstract}

O primeiro momento do parágrafo indica que a salvação comum justifica que se viole o contrato, que se rompa com o soberano que cria o direito civil. Este juízo de violação não cabe, entretanto, afirma o texto, a um privado. Ora, qual o critério, pois, dessa ocorrência? O critério é o seguinte: se não violar as leis significa que o medo comum, da maioria dos cidadãos, ocasionado exatamente por atos do poder soberano ou por conteúdos de leis dele emanadas, se transmutará em indignação, a cidade já se dissolveu. Assim, não resta mais qualquer direito civil como critério da justiça, mas apenas o direito de guerra de lado a lado. Nesta situação, nem o cidadão, nem o poder soberano, devem respeito ao contrato. $\mathrm{O}$ poder soberano lutará (com a potência que lhe restar, dado que o medo comum da maioria se transmutou em indignação) para restaurar a potência originária que lhe dava a ocasião de fazer as leis, o direito civil, critério do justo. E cada cidadão lutará - em razão de um direito de guerra que se apresenta nestas específicas situações de conversão do medo comum da maioria em indignação, esfacelando o equilíbrio de potências que caracteriza a Civitas - para que o poder soberano, que não mais faz jus à sua razão de ser, se estiole, e outra configuração de cidade se apresente no campo de lutas da política ${ }^{19}$.

\footnotetext{
${ }^{18}$ Neste momento do texto (TP II 17, p. 20), Espinosa afirma que se este poder, esta incumbência da república, pertencer a um conselho que é composto pela multidão comum, tem-se o imperium democrático [o estado chamase democracia], se for composto por alguns eleitos, tem-se o imperium aristocrático [aristocracia] e, por fim, se pertence a um só, tem-se o imperium monárquico [monarquia].

${ }^{19}$ Afirmam sobre esta questão, na mesma linha da interpretação aqui proposta, GUIMARAENS e ROCHA, 2014: "A violação do consenso ou sua não renovação constituem causas de ruína do Estado [ou seja, da Civitas] e autorizam o exercício do direito de resistência pela multidão. Na verdade, a contínua produção da aceitação de um determinado governo é essencial para que a dinâmica afetiva seja favorável à obediência política. Na base da obediência se encontra um conjunto de afetos tendentes a ela. Assim, no momento em que cessa a disposição afetiva de obedecer e se alastra a indignação, a resistência não apenas é desejável, mas necessária.” (p. 202). Na mesma linha argumentativa, levantando a questão de que a multidão não tem obrigação de respeitar o pacto e o
} 
Em síntese, o direito civil, que permite, na cidade, dizer o seu de cada um, não é qualquer direito civil, mas demanda que se compreenda a fina elaboração espinosana acima analisada, a qual, é certo, tem como centro a necessidade de um conceito de direito civil que seja função da garantia da potência dos súditos-cidadãos constituintes da Civitas. O termo aparentemente solto ao final do escólio 2 da Proposição 37, a saber, "consenso comum [ubi ex communi consensu decernitur]" (ESPINOSA, 2015, pp. 436-439 - E IV P 37 Esc 2), ganha novas cores e importância ao ser analisado à luz da argumentação acima desenvolvida. O consenso comum é um consenso afetivo, de potências, que sustenta o poder soberano, o qual detém o direito da cidade. Findo este consenso, a cidade se dissolve pela transmutação do medo comum da maioria em indignação.

Haveria outros conceitos de justiça no corpus espinosano, especialmente nas duas obras políticas?

No Tratado Político, sua última obra, Espinosa escreve algo que corrobora a tese de que há apenas um sentido do conceito de justo e injusto em seu sistema, ao menos como definição proposta pelo autor, e isso tanto na Ética quanto nas obras políticas: ${ }^{20}$

No nosso Tratado Teológico-Político tratamos do Direito Natural e do Direito Civil, e na nossa Ética explicamos o que é o pecado, o mérito, a justiça, a injustiça e, finalmente, a liberdade humana. Mas para que os que leem o presente tratado não tenham o trabalho de ir procurar noutros aquelas coisas que respeitam mormente a este, proponho-me explicá-las de novo aqui e demonstrá-las apoditicamente. (ESPINOSA, 2009, p. 11 - TP II 1 - grifos meus)

Espinosa não afirmaria tal tese se tivesse desenvolvido mais de um conceito de justiça em sua obra. Há ao menos dois argumentos nesse sentido no excerto citado. Primeiro: de que na Ética já teria explicado estes conceitos. Com efeito, como analisado no correr deste artigo, foi o que fez. Segundo: o fato de que afirma, ao final do excerto, que os explicará novamente para que o leitor não tenha que recorrer às outras obras. E, realmente, no Político (ESPINOSA, 2009, p. 23 - TP, II, 23), reitera o que dissera na Ética, a saber, a justiça apenas pode conceberse no estado (outro nome da Civitas). O parágrafo 23 do capítulo II resume os argumentos

direito civil no caso em que o imperium deixa de respeitar sua razão de ser, a saber, o bem-estar dos cidadãos, ver ANDRADE, 2001, pp. 274-277.

${ }^{20}$ André Santos Campos trata do tema, como já indicado em nota anterior. Ver: CAMPOS, 2016, pp. 127-143. Para Campos, seriam vários os sentidos do termo na obra espinosana. Ver uma suma dos sentidos do termo na nota de rodapé 3 do artigo, bem como os contextos em que Espinosa usa o termo (p. 128). Porém, pelo excerto citado a seguir, da última obra de Espinosa, o Tratado político, o sentido parece ser unívoco no corpus - essa a hipótese levantada no presente artigo. 
presentes na Ética (ESPINOSA, 2015, pp. 435-439 - E IV P 37 Esc 2) sem qualquer distância na definição em uma obra e na outra.

No Tratado Teológico-Político (TTP), por sua vez, obra publicada anonimamente em 1670, aparecem vários sentidos do termo justo e outros do mesmo campo semântico (justa, justiça, injustiça etc.). Entretanto, não se pode desconsiderar os contextos. Às vezes Espinosa dá definição que não é a sua, mas de algum outro sistema ou de outro texto, como o bíblico (ESPINOSA, 2003, p. 35, p. 41 - TTP, II, entre outras). Nesse sentido, não se pode dizer que se trata, em todos os casos que se apresentam no texto, da definição espinosana. Por sua vez, o sentido que Espinosa dá ao termo, como definição sua, igualmente é o mesmo que depois aparecerá na Ética e no Político. Veja-se o Prefácio do TTP:

Em seguida, mostro que os que detêm o poder soberano são os garantes e os intérpretes, não só do direito civil, mas também do direito sagrado, e que só eles possuem o direito de discernir o que é justo e o que é injusto, o que é piedoso e o que é ímpio, concluindo, enfim, que a melhor maneira de poderem manter esse direito e conservar o Estado em segurança é consentirem que cada um pense aquilo que quiser e diga aquilo que pensa. (ESPINOSA, 2003, pp. 13-14 - TTP, Prefácio).

O mesmo sentido aparece em TTP IV. Afirma Espinosa:

[...] mas aquele que dá a cada um o que lhe é devido por conhecer a verdadeira razão das leis e a sua necessidade age com ânimo perseverante, por sua própria decisão e não por decisão de outrem, merecendo por isso que lhe chamem justo. Foi o que Paulo, segundo creio, quis também ensinar quando disse que os que viviam subjugados pela lei não podiam ser justificados pela lei: a justiça, com efeito, tal como é vulgarmente definida, é a constante e perpétua vontade de dar a cada um o que lhe é devido. (ESPINOSA, 2003, p. 68) $)^{21}$

E, de modo mais explícito, em TTP XVI: “A justiça é a disponibilidade constante para atribuir a cada um aquilo que, de acordo com o direito civil, lhe é devido; a injustiça, pelo contrário, consiste em tirar a alguém, sob uma falsa aparência de direito, o que lhe pertence segundo a verdadeira interpretação das leis.” (ESPINOSA, 2003, p. 243$)^{22}$.

Mesmo na correspondência, na mesma toada argumentativa acima exposta, Espinosa não muda sua posição sobre o conceito de justiça. Com efeito, na carta 23 , de 13 de março de 1665, escreve a Blyenbergh, em querela sobre o ladrão e o justo, se teriam a mesma beatitude, se seriam igualmente perfeitos, o que segue:

Perguntai se o ladrão e o justo são igualmente perfeitos, se têm a mesma beatitude? Respondo: não. Por justo, com efeito, entendo aquele que deseja constantemente que cada um tenha o que é seu e em minha Ética (ainda não publicada) demonstro que esse desejo, nos homens piedosos, extrai necessariamente sua origem do conhecimento que possuem de si mesmos e de Deus. (ESPINOSA, 2014, p. 148 - Ep. 23).

\footnotetext{
${ }^{21} \mathrm{O}$ mesmo conceito em ESPINOSA, 2003, p. 122 - TTP, VII.

${ }^{22}$ No mesmo sentido, ESPINOSA, 2003, pp. 288-289 e p. 303 - TTP, XIX, bem como TTP, XX, respectivamente.
} 
Mesma definição, portanto, presente nas obras políticas e na Ética, a qual foi citada como fonte do conceito de justiça.

Assim, voltando ao momento do corpus em que o autor trata de maneira detalhada do conceito, a saber, E IV P 37 Esc 2, o que o diferencia da tradição aristotélica e romana que chega a São Tomás de Aquino? Mesmas palavras, fundamentos diversos, como se procurou mostrar acima, com o uso de alguns outros conceitos da obra espinosana que são fundamentais à compreensão do conceito de justiça.

De fato, procurei mostrar que "a vontade constante e perpétua de atribuir a cada um o que é seu" só faz sentido se o direito civil da cidade, critério do seu de cada um, não ocasione a transmutação do medo da maioria dos cidadãos, o medo civil, em indignação em face do soberano que promulga este mesmo direito civil. E tal indignação pode se dar seja porque os conteúdos das leis advindas do soberano abominam à natureza humana, seja porque as ações dos membros do poder soberano levam ao surgimento desse afeto, massivamente, nos cidadãos.

Portanto, o conceito de justiça em Espinosa só faz sentido à luz da ontologia da substância única, Deus sive natura, da qual os homens são modos finitos, intensidades de potência. Não há o formalismo, em certo sentido abstrato, de São Tomás de Aquino. Toda uma construção ontológica informa o tema do justo em Espinosa. E tal conceito, na definição proposta pelo autor como de sua autoria, eis um dos aspectos da hipótese aqui lançada, é um, e apenas um, no corpus espinosano.

\section{REFERÊNCIAS BIBLIOGRÁFICAS}

ANDRADE, F. D. Pax spinozana: direito natural e direito justo em Espinosa. Tese apresentada ao Departamento de Filosofia da FFLCH USP. São Paulo: 2001. Disponível em: http://www.teses.usp.br/teses/disponiveis/8/8133/tde-18082017-120726/pt-br.php. Acesso em: 28 AGO 2020 [2001].

AQUINO, TOMÁS DE. Suma Teológica. Vol. IV. Vários tradutores. São Paulo: edições Loyola, 2010 [I IIae].

AQUINO, TOMÁS DE. Suma Teológica. Vol. VI. Vários tradutores. São Paulo: edições Loyola, 2012 [II IIae].

AQUINO, TOMÁS DE. Suma Contra os Gentios. Tradução de Dom Odilão Moura (OSB). Campinas: Ecclesiae, 2017.

BITTAR, E. C. B. Direito e Justiça em São Tomás de Aquino. In: Revista da Faculdade de Direito, Universidade de São Paulo, São Paulo, Vol. 93, jan - 1998, pp. 339-359.

CAMPOS, A.S. Spinoza on justice: understanding the suum cuique. In: Epoché, Vol. 21, Issue 1, 2016, pp. 127-143. 
CAMPOS, A.S. Ius sive potentia. Individuação jurídico-política na filosofia de Spinoza. Tese apresentada ao Departamento de Filosofia da Faculdade de Letras da Universidade de Lisboa. Lisboa, 2008.

CHAUI, M. Medo e esperança, guerra e paz. In: Desejo, paixão e ação na Ética de Espinosa. São Paulo: Companhia das Letras, 2011, pp. 173-191.

DELEUZE, Gilles. Cursos sobre Spinoza (Vincennes, 1978-1981). Seleção e Introdução de Emanuel Angelo da Rocha Fragoso e Hélio Rebello Cardoso Júnior. Tradução Emanuel Angelo da Rocha Fragoso; Francisca E. B. de Castro, Hélio R. C. Júnior, Jefferson A. de Aquino. Fortaleza: ed. UECE, 2009.

ESPINOSA. Spinoza Opera. Ed. de Carl Gebhardt. Heidelberg: Carl Winter, 4 vols, 1972 [1 ${ }^{\text {a }}$ ed. 1925].

ESPINOSA. Ética. Tradução de Tomaz Tadeu. Belo Horizonte: Autêntica, 2008.

ESPINOSA. Ética. Tradução do Grupo de Estudos Espinosanos. São Paulo: Edusp, 2015.

ESPINOSA. Correspondência. Tradução e notas de J. Guinsburg e Newton Cunha. São Paulo: Perspectiva, 2014.

ESPINOSA. Tratado Teológico-Político. Tradução, introdução e notas de Diogo Pires Aurélio. São Paulo: Martins Fontes, 2003.

ESPINOSA. Tratado Político. Tradução, introdução e notas de Diogo Pires Aurélio. São Paulo: M. Fontes, 2009.

GUIMARAENS, Francisco de e ROCHA, Maurício. Spinoza e o Direito de Resistência. In: Sequência, Florianópolis, n. 69, pp. 183-214, DEZ 2014.

JUSTINIAN. The Digest of Justinian. Vol. 1. Translated by Alan Watson. Philadelphia: University of Pensylvania Press, 1998 [1st ed. 1985].

JUSTINIANO. Corpus Iuris Civilis - Digesto. Edição bilíngue. Tradução de Edilson Alkmim Cunha. Brasília: TRF1, ESMAF, 2010.

MAQUIAVEL. O Príncipe. Edição bilíngue. Tradução de José Antônio Martins. São Paulo: ed. Hedra, 2011.

MONTANS BRAGA, L. C. A política e os afetos: a concepção espinosana. In: Revista Direito \& Práxis, Rio de Janeiro, Vol. 8, n. 3, 2017, pp. 2010-2042. Disponível em: https://doi.org/10.1590/2179-8966/2017/24762. Acesso em: 03 MAR 2021.

MONTANS BRAGA, L.C. Indignação, política e direito em Espinosa. In: Quaestio Iuris, Rio de Janeiro, Vol. 11, n. 2, 2018, pp. 1037-1051.

MONTANS BRAGA, L.C. Agudíssimo: Maquiavel em Espinosa. In: Pensando - Revista de Filosofia, Teresina, Vol. 10, n. 21, 2019, pp. 67-78.

REIS, N.H.N. David Hume e suas inconfessáveis relações com Maquiavel. In: Revista Estudos Hum(e)anos, Belo Horizonte/Rio de Janeiro, Vol. 7, n. 2, 2019, pp. 73-94.

VALVERDE, A. J. R. Apontamentos à fortuna crítica de Il Principe, de Machiavelli: de Gentillet a Gramsci e a recepção brasileira. In: Pensando - Revista de Filosofia, Teresina, Vol. 10, n. 21, 2019, pp. 26-43. 